\title{
Influence of high range of mass transfer coefficient and convection heat transfer on direct contact membrane distillation performance
}

\author{
Jung-Gil Lee ${ }^{\mathrm{a}}$, Sanghyun Jeong ${ }^{\mathrm{a}, \mathrm{b}}$, Ahmad S. Alsaadi ${ }^{\mathrm{a}}$, Noreddine Ghaffour ${ }^{\mathrm{a},{ }^{*}}$ \\ ${ }^{a}$ King Abdullah University of Science and Technology (KAUST), Water Desalination and Reuse Center (WDRC), \\ Biological and Environmental Science \& Engineering (BESE), Thuwal 23955-6900, Saudi Arabia \\ ${ }^{b}$ Graduate School of Water Resources, Sungkyunkwan University (SKKU), 2066, Seobu-ro, Jangan-gu, Suwon-si, \\ Gyeonggi-do, 16419, Republic of Korea \\ *Corresponding author: Tel. +966-128082180,Email: noreddine.ghaffour@kaust.edu.sa
}

\begin{abstract}
In order to improve water production of membrane distillation (MD), the development of high performance membrane having better mass transfer and enhancement of convection heat transfer in MD module have been continuously investigated. This paper presents the relationship between the heat and mass transfer resistance across the membrane and the performance improvement. Various ranges of mass transfer coefficient (MTC) from normal $\left(0.3 \times 10^{-6}\right.$ to $2.1 \times 10^{-6} \mathrm{~kg} / \mathrm{m}^{2} \mathrm{sPa}$ : currently available membranes) to high $\left(>2.1 \times 10^{-6} \mathrm{~kg} / \mathrm{m}^{2} \mathrm{sPa}\right.$ : membranes under development) were simulated using an experimentally validated model at different ranges of convection heat transfer by varying the inlet flow rates and spacer enhancement factor. The effect of mass transfer and convection heat transfer on the MD performance parameters including temperature polarization coefficient (TPC), mean permeate flux, and specific energy consumption were investigated in a direct contact MD (DCMD) configuration. Results showed that improving the MTC at the low ranges is more important than that at the high ranges where the heat transfer resistance becomes dominant and hence the convection heat transfer coefficient must be increased. Therefore, an effort on designing MD modules using feed and permeate spacers and controlling the membrane surface roughness to increase the convection heat transfer and TPC in the channel aiming to enhance the flux is required because the currently developed mass transfer has almost reached the critical point.
\end{abstract}


Keywords: Desalination; Optimized MTC; MD performance; Mean permeate flux; Specific energy consumption.

\section{Introduction}

Membrane distillation (MD) is a thermally driven process that uses a hydrophobic microporous membrane as a contactor between two fluids at different temperatures. MD has been tested for different applications, such as desalination and industrial wastewater treatment [1-3]. It has gained researchers attention as one of the next-generation desalination techniques owing to the benefits it has compared to the avialable conventional systems, which include: (i) operates at low temperature (relative to thermal desalination process); (ii) operates at lower hydraulic pressure (relative to reverse osmosis (RO) process); (iii) has higher boron and other compounds removal efficiency (relative to RO); (iv) needs low footprint; and (v) has lower sensitivity to feed salinity [1, 4-10]. However, low water production (flux) with larger modules is one of its limitations which makes its scale-up and commercialization challenging [3, 11-13].

Several studies were focused on increasing MD water production. Researchers have also attempted to fabricate novel MD membranes aiming to improve its mass transfer coefficient (MTC), while other groups tried to optimize the process by looking at the optimal operation conditions that yield better flux with lower energy requirement. A proper MD membrane needs to have [14]: (i) high permeability, (ii) lower thermal conductivity, (iii) high hydrophobicity (high water contact angle), (iv) narrow pore size distribution, (v) high mechanical strength, (vi) excellent chemical resistance and (vii) good thermal stability. In theory, the MTC increases with increasing the mean pore size and porosity and decreases with increasing membrane thickness. Furthermore, it increases with an approaching to the lowest tortuosity value (1.0) [1,3]. MTC, which is usually set by the structural parameter of microporous hydrophobic membrane, is the most important factor for the MD performance. It consists of the value of the resistance of water vapor transport

through the microporous membrane, which makes it affecting the overall MD performance, such as temperature polarization coefficient (TPC), mean permeate flux (MPF), and specific energy consumption. The latter (see S19)) is one of the standard parameters for the performance similar to the gained output ratio (GOR) in $\mathrm{kWh} / \mathrm{kg}$. Therefore, the development of novel membrane having higher MTC is required to overcome the low water production [15-20]. Development of non-polymeric materials embedded membranes (i.e., carbon nanotubes (CNTs)) integrating 
nanomaterials into polymeric materials have been attempted to improve the membrane's MTC [15, 16, 21]. Double-layer membranes have also been investigated as a potential MD composite membrane where the enhanced MTC is achieved through making the active layer as thin as possible [1, 14, 17-20]. With the continual development of novel membranes, various MTCs are being reported and the highest value reported in the MD literature so far is $2.15 \times 10^{-6} \mathrm{~kg} / \mathrm{m}^{2} \mathrm{sPa}$ [11], as shown in Table 1. Although it was reported in 2011 [11], the $2.15 \times 10^{-6} \mathrm{~kg} / \mathrm{m}^{2} \mathrm{sPa}$ value is still considred at the highest level, so far [5].

Table1. Reported DCMD membrane MTC [11]. DI water was used as feed solution.

\begin{tabular}{lll}
\hline Membrane material & Pore size $(\mu \mathrm{m})$ & MTC $\left(\mathrm{kg} / \mathrm{m}^{2} \mathrm{sPa}\right)$ \\
\hline PTFE & 0.20 & $1.45 \times 10^{-6}$ \\
& 0.45 & $2.15 \times 10^{-6}$ \\
PVDF & 0.22 & $3.8 \times 10^{-7}$ \\
Enka (pp) & 0.10 & $4.5 \times 10^{-7}$ \\
Enka (pp) & 0.20 & $4.3 \times 10^{-7}$ \\
PVDF & 0.45 & $4.8 \times 10^{-7}$ \\
GVHP & 0.22 & $4.919 \times 10^{-7}$ \\
HVHP & 0.45 & $6.613 \times 10^{-7}$ \\
\hline
\end{tabular}

The optimization of MD operating conditions can reduce the effects of concentration polarization and temperature polarization. It was reported that $\mathrm{CP}$ effect can be negligible in the MD process $[8,22]$, while temperature polarization was considered as one of the main issues that can lower MD performance since it is significantly affecting the driving force (i.e. water vapor pressure) $[1,23,24]$. This phenomenon is caused by the temperature difference with bulk and liquid/vapor interface on the membrane surface. In addition, due to the lack of measuring technique for the transmembrane temperature, the theoretical simulation study of MD process is necessary. And through the simulation study, the temperature polarization coefficient as a key factor of MD process can be estimated (see Eq. (S20)). Therefore, recent studies have been focused on reducing temperature polarization effect by improving convective heat transfer in the flow channel without increasing the inlet flow rate (even at laminar flow). The use of polymeric spacers [25-31] and the enhancement of membrane surface roughness [32-34] act as turbulence promoter techniques to improve the convection heat transfer coefficient. 
Generally, higher MTC and convection heat transfer coefficient can lead to high MD performance. However, the latter cannot be expected to have a proportional increase with an increase of MTC and convection heat transfer coefficient due to the balance of heat and mass transfer. Thus, research is required to achieve a better understanding of the effect of these two parameters on the MD performance and to subsequently improve it. In this study, the theoretical simulations at various ranges of these coefficients were conducted to investigate their effects on TPC, mean permeate flux, and specific energy consumption. Results of this study show the predictable results however, to our knowledge it is not reported in the literature. The effect of heat and mass transfer on the direct contact MD (DCMD) process is necessary to be explained and reported using a variety of thermal and MTCs. This study also tried to provide research and development guidelines aiming to set ranges at which these parameters are more or less effective in enhancing the MD process performance. The investigation was assessed using a small-scale DCMD unit. An extensively and experimentally validated theoretical based simulation model under different conditions $[1,4,35]$ consisting of mass, momentum and energy balances in the bulk feed and permeate channel flows was employed (see more details in the supplementary information).

\section{Scenarios for DCMD simulation}

In all simulated scenarios, a lab-scale DCMD process setup was considered and its operational parameters are as follows:

(i) Feed and permeate flows are circulated in a counter-current manner at the same flow rate.

(ii) The dimensions of membrane module channel are $5 \mathrm{~cm} \times 10 \mathrm{~cm} \times 0.3 \mathrm{~cm}$ (width $\times$ length $\times$ depth) with an effective membrane surface area of $50 \mathrm{~cm}^{2}$.

(iii) The pseudo properties of the microporous hydrophobic MD membrane and operating conditions used for this study are given in Tables 2 and 3, respectively. A small lab-scale module was used in this study to avoid the prediction error for scaling up.

The thermal conductivity coefficient $(0.25 \mathrm{~W} / \mathrm{mK})$ and thickness of the membrane $(100 \mu \mathrm{m})$ were employed as normal values (Table 2). The thermal conductivity coefficients of hydrophobic polymers at $23{ }^{\circ} \mathrm{C}$ are $0.17-0.21 \mathrm{~W} / \mathrm{mK}$ (polypropylene, PP), $0.19 \mathrm{~W} / \mathrm{mK}$ (Polyvinylidene fluoride, PVDF), and $0.25 \mathrm{~W} / \mathrm{mK}$ (Polytetrafluoroethylene, PTFE). MTC values were categorized as (i) developed, based on Table $1\left(0.3 \times 10^{-6} \mathrm{~kg} / \mathrm{m}^{2} \mathrm{sPa}\right.$ to $2.1 \times 10^{-6} \mathrm{~kg} / \mathrm{m}^{2} \mathrm{sPa}$, referred as normal $)$, and 
(ii) to be developed $\left(2.1 \times 10^{-6} \mathrm{~kg} / \mathrm{m}^{2} \mathrm{sPa}\right.$ to $6.3 \times 10^{-6} \mathrm{~kg} / \mathrm{m}^{2} \mathrm{sPa}$, referred as high). It is reported that the MTC is not only determined by the structural parameter of hydrophobic membrane but also the characteristic of hydrophobic membrane [21]. Therefore, it is believed that the MTC can be increased over the limitation of structural theory. The normal ranges of operating conditions were also employed. The membrane thicknesses were not provided in a privious study [11]. However, most hydrophobic membranes used in the MD process possess thicknesses ranging from $10 \mu \mathrm{m}$ to $200 \mu \mathrm{m}$ [5]. Thus, in this study, the membrane thickness was assumed to $100 \mu \mathrm{m}$. As shown in Eq. (S1), the MTC of membrane is associated with the structural parameters which means that the hydrophobic membrane having the proper pore radius, the high porosity, the proper tortuosity $(\tau \approx$ 1), and low thickness can have high MTC. In addition, mechanically and chemically strong membrane is also essential. The modified convection heat transfer coefficient as spacer factor $\left(k_{d c}=C H T_{m}\right)$ was calculated and employed based on reference [36]. It can be calculated by Eqs. (S7) - (S11). In addition, the normal and modified convection heat transfer coefficients of inlet feed and permeate side according to the various operating conditions given in this study are presented in Table.4.

Table 2. Properties of the pseudo hydrophobic microporous membrane (assumed for this study).

\begin{tabular}{lll}
\hline Property & Unit & Hydrophobic pseudo microporous membrane \\
\hline MTC $(C)$ & $\mathrm{kg} / \mathrm{m}^{2} \mathrm{sPa}$ & $0.3 \times 10^{-6}-6.3 \times 10^{-6}$ \\
& & $\begin{array}{l}\text { Developed based on reported values: } \\
\end{array}$ \\
& & $0.3 \times 10^{-6}$ to $2.1 \times 10^{-6}$, Normal \\
& & To be developed: $2.1 \times 10^{-6}$ to $6.3 \times 10^{-6}$, High \\
Thermal conductivity of Membrane $\left(k_{m}\right)$ & $\mathrm{W} / \mathrm{mK}$ & 0.25 (Assumed PTFE) \\
Thermal conductivity of Air $\left(k_{a}\right)$ & $\mathrm{W} / \mathrm{mK}$ & 0.026 \\
Porosity $(\varepsilon)$ & $\%$ & 80 \\
Thickness $(\delta)$ & $\mu \mathrm{m}$ & 100 \\
\hline
\end{tabular}

Table 3. Detailed operating conditions for DCMD process ( $\mathrm{F}$ and $\mathrm{P}$ represent the feed and permeate, respectively).

\begin{tabular}{lll}
\hline Parameters & Unit & Value \\
\hline Temperature & ${ }^{\circ} \mathrm{C}$ & $60(\mathrm{~F})$ and $30(\mathrm{P})$ \\
Flow velocity & $\mathrm{m} / \mathrm{s}$ & 0.044 to $0.222(\mathrm{~F}$ and P)
\end{tabular}


Feed salinity

$\mathrm{g}$ of $\mathrm{NaCl} / \mathrm{L} \quad 40$

Modified convection heat transfer coefficient of feed inlet $\left(\mathrm{CHT}_{\mathrm{f} \text { and,p, }}{ }^{1)}\right) \quad$ Times $(\times) \quad 1.0$ to $1.5(\mathrm{~F}$ and $\mathrm{P})$

1) Flow rates of both feed and permeate sides $=2.0 \mathrm{~L} / \mathrm{min}$.

Table. 4 Convection heat transfer coefficients according to the flow velocity and modified convection heat transfer $\left(\mathrm{CHT}_{\mathrm{m}}\right)$.

\begin{tabular}{ccc}
\hline W/O spacer & Range & $\begin{array}{c}\text { Convection heat transfer coefficient } \\
\left(\mathrm{W} / \mathrm{m}^{2} \mathrm{~K}\right)\end{array}$ \\
\hline Without spacer & $\begin{array}{c}\text { Flow velocity } \\
\text { at feed and permeate flow velocity } \\
\text { from } 0.044 \text { to } 0.222 \mathrm{~m} / \mathrm{s}\end{array}$ & $\begin{array}{c}\text { Feed (F): } 950.47 \text { to } 1625.28 \\
\text { Permeate }(\mathrm{P}): 929.10 \text { to } 1588.74\end{array}$ \\
& $\begin{array}{c}C H T_{m}=k_{d c} \text { from } 1.0 \text { to } 1.5 \\
\text { at } 0.222 \mathrm{~m} / \mathrm{s} \text { of feed and permeate } \\
\text { flow spacer }\end{array}$ & Feed (F): 2486.51 to 3729.75 \\
& Permeate $(\mathrm{P}): 2470.83$ to 3706.22 \\
\hline
\end{tabular}

In this study, the modified convection heat transfers $\left(\mathrm{CHT}_{\mathrm{m}}=\mathrm{k}_{\mathrm{dc}}\right)$ ranging from 1.0 to 1.5 were employed and calculated by the structural parameter of spacer. In order to apply various ranges of modified convection heat transfer, the angles between filaments, $\theta$ are adjusted from $\approx 0$ to 90 . Figure 1 shows a schematic diagram of PP spacer and its specifications are given in Table 5. In addition, due to the installation of spacer, the channel structural parameters are changed, thus the modified equations are applied (See Eqs. S9-S11, S14, S16-S19).

Table 5. Specifications of the spacers [1].

\begin{tabular}{ll}
\hline Material & PP \\
\hline Spacer thickness, $h_{s}(\mathrm{~mm})$ & 0.8 \\
Filaments diameter, $d_{f}(\mathrm{~mm})$ & 0.4 \\
Angle between filaments, $\theta(\mathrm{deg})$ & From $\approx 0$ to 90 \\
Mesh size, $l_{m}(\mathrm{~mm})$ & 2 \\
\hline
\end{tabular}



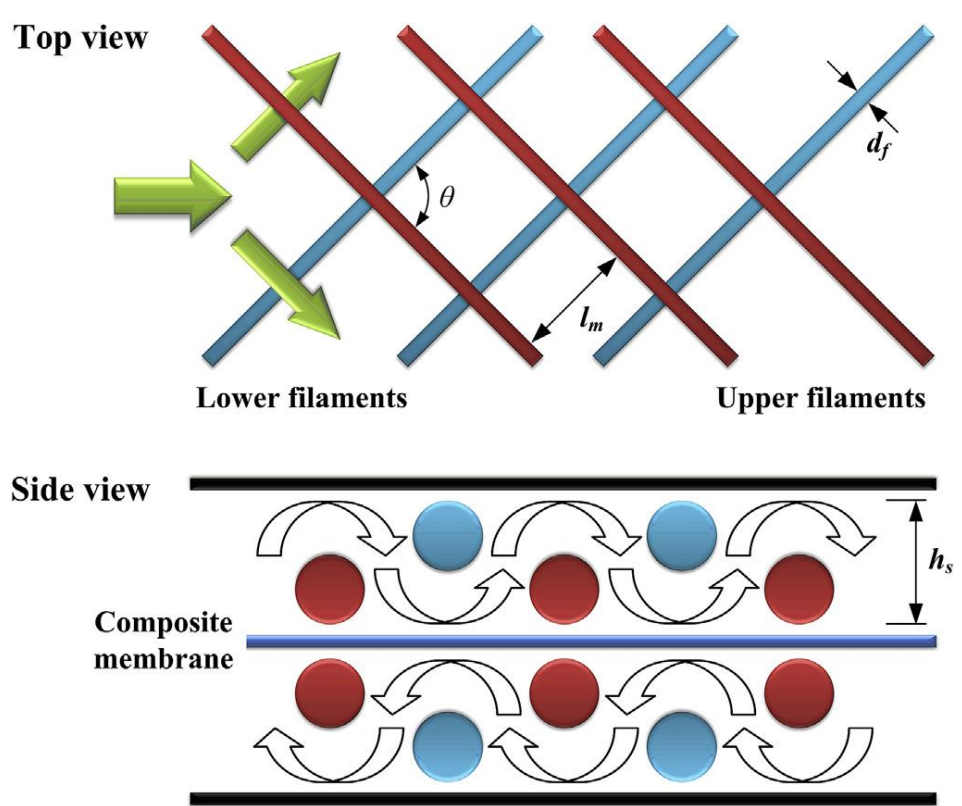

Figure 1. Geometric characteristics of a non-woven net spacer and flow pattern in a spacer-filled channel [41].

\section{Theoretical model and validation}

A one-dimensional (1D) theoretical model considering heat and mass transfer and transport behavior simultaneously, previously validated experimentally, was employed in the simulation study. The model used was validated under different conditions elsewhere [1,35, 37-41]. Transport behavior considered all the momentum, mass and energy balances at both feed and permeate sides. Detailed theoretical equations are denoted in the supplementary information. This model could predict temperatures, velocities, salinities and pressures distribution along the axial distance of the module. Hence, TPC, mean permeate flux and specific energy consumption in DCMD operation could also be calculated using this model. In addition to the MTC, the transmembrane temperature difference is an important factor to determine the MD performance as it represents the driving force. Temperatures of liquid/vapor interfaces at feed and permeate flows which cannot be measured experimentally were also predicted using the simulation study.

\section{Results}

\subsection{Influence of flow rate and mass transfer coefficient}

The simulation study was conducted to investigate the effects of flow rate (in this study represented as the convection heat transfer coefficient) and MTC on the MD performance in terms 
of TPC, mean permeate flux and specific energy consumption at inlet feed and permeate temperatures of $60^{\circ} \mathrm{C}$ and $30^{\circ} \mathrm{C}$, respectively, inlet feed and permeate flow rates ranging from 0.4 to $2.0 \mathrm{~L} / \mathrm{min}$, and feed salinity of $40 \mathrm{~g} / \mathrm{L}$ (typical Red Sea water). The feed and permeate flow velocities $(\mathrm{m} / \mathrm{s})$ can be calculated by dividing the inlet flow rate $(\mathrm{L} / \mathrm{min})$ by the water density $\left(\mathrm{kg} / \mathrm{m}^{3}\right)$ and inlet channel area $\left(\mathrm{m}^{2}\right)$. Therefore, the low channel thickness can increase the convection heat transfer as well as flow velocity. The convection heat transfer coefficient can be calculated by using Eqs. (S7) - (S11). Temperature and type of solution can affect it, however, in this study, due to the use of a fixed inlet feed and permeate temperatures (seawater and distilled water), the flow velocity affects dominantly on the convection heat transfer coefficient. Typically, the theoretical MTC calculation considers temperature and pressure together (see Eq. (S1)). However, in this study, constant MTC values ranging from $0.3 \times 10^{-6}$ to $2.1 \times 10^{-6} \mathrm{~kg} / \mathrm{m}^{2} \mathrm{sPa}$ (normal) without their variations along the module length were employed as the model used was not sufficient to make a significant difference in small effective area. As mentioned above, development of membranes has led to an increase of MTC and so far the highest reported value in the literature is $2.15 \times 10^{-6} \mathrm{~kg} / \mathrm{m}^{2} \mathrm{sPa}$ [11]. In this paper, MTC varying from $0.3 \times 10^{-6}$ to $6.3 \times 10^{-6}$ $\mathrm{kg} / \mathrm{m}^{2} \mathrm{sPa}$, split into two zones, i.e. values from $0.3 \times 10^{-6}$ to $2.1 \times 10^{-6} \mathrm{~kg} / \mathrm{m}^{2} \mathrm{sPa}$ and from $2.1 \times 10^{-6}$ to $6.3 \times 10^{-6} \mathrm{~kg} / \mathrm{m}^{2} \mathrm{sPa}$ are reffered as normal and high MTC, respectively, is investigated (zones represented in the next figures).

Figure 2a-c (normal zone) show the effects of flow rate (from 0.4 to $2.0 \mathrm{~L} / \mathrm{min}$ ) and MTC (from $0.3 \times 10^{-6}$ to $2.1 \times 10^{-6} \mathrm{~kg} / \mathrm{m}^{2} \mathrm{sPa}$ ) on (a) TPC, (b) mean permeate flux and (c) specific energy consumption at a given operating conditions. As can be seen from Figure 3 a (normal zone), at a flow rate of $0.4 \mathrm{~L} / \mathrm{min}$, the TPC decreased from 0.24 to 0.11 with an increase of MTC from 0.3 to $2.1 \times 10^{-6} \mathrm{~kg} / \mathrm{m}^{2} \mathrm{sPa}$ and it decreased from 0.44 to 0.22 at the highest flow rates of $2.0 \mathrm{~L} / \mathrm{min}$. The TPC increased about $81 \%$ (from 0.24 to 0.44 ) with an increase of flow rate by 5 times (0.4 to 2.0 $\mathrm{L} / \mathrm{min}$ ) even at the lowest MTC value of $0.3 \times 10^{-6} \mathrm{~kg} / \mathrm{m}^{2} \mathrm{sPa}$, tested in this study. Moreover, at the MTC of $2.1 \times 10^{-6} \mathrm{~kg} / \mathrm{m}^{2} \mathrm{sPa}$, further increase of TPC $(\approx 89 \%)$ has been achieved showing that the convection heat transfer coefficient (which is an affecting factor of the flow rate as mentioned above) was influenced more on TPC at higher MTC values. On the other hand, the mean permeate flux increased from 2.99 to $6.85 \mathrm{~kg} / \mathrm{m}^{2} \mathrm{~h}$ and from 8.70 to $22.31 \mathrm{~kg} / \mathrm{m}^{2} \mathrm{~h}$ with an increase of flow rates from 0.4 to $2.0 \mathrm{~L} / \mathrm{min}$, respectively, in respect of the increase in MTC (from 0.3 to $2.1 \times 10^{-6}$ $\mathrm{kg} / \mathrm{m}^{2} \mathrm{sPa}$ ) (Figure $2 \mathrm{~b}$ (normal zone)). Finally, the specific energy consumption decreased from 
2.31 to $1.99 \mathrm{kWh} / \mathrm{kg}$ with an increase of MTC from 0.3 to $2.1 \times 10^{-6} \mathrm{~kg} / \mathrm{m}^{2} \mathrm{sPa}$ at a flow rate of 0.4 $\mathrm{L} / \mathrm{min}$ and it also decreased from 0.91 to $0.84 \mathrm{kWh} / \mathrm{kg}$ at $2.0 \mathrm{~L} / \mathrm{min}$ (Figure 2c (normal zone)).

In this section, the MD performance behavior was studied in terms of TPC, mean permeate flux and specific energy consumption with up to date developed or reported MD membranes with various MTC $\left(0.3 \times 10^{-6}\right.$ to $\left.2.1 \times 10^{-6} \mathrm{~kg} / \mathrm{m}^{2} \mathrm{sPa}\right)$. The mean permeate flux increase was significant with an increase in the normal ranges of MTC, while the specific energy consumption and TPC decreased sharply. The progress of membrane fabrication technology has continuously directed to the increase of MTC. Therefore, an additional study on the performance behavior with higher MTC has to be considered to provide an appropriate guideline for the MD performance improvement along with membrane development.

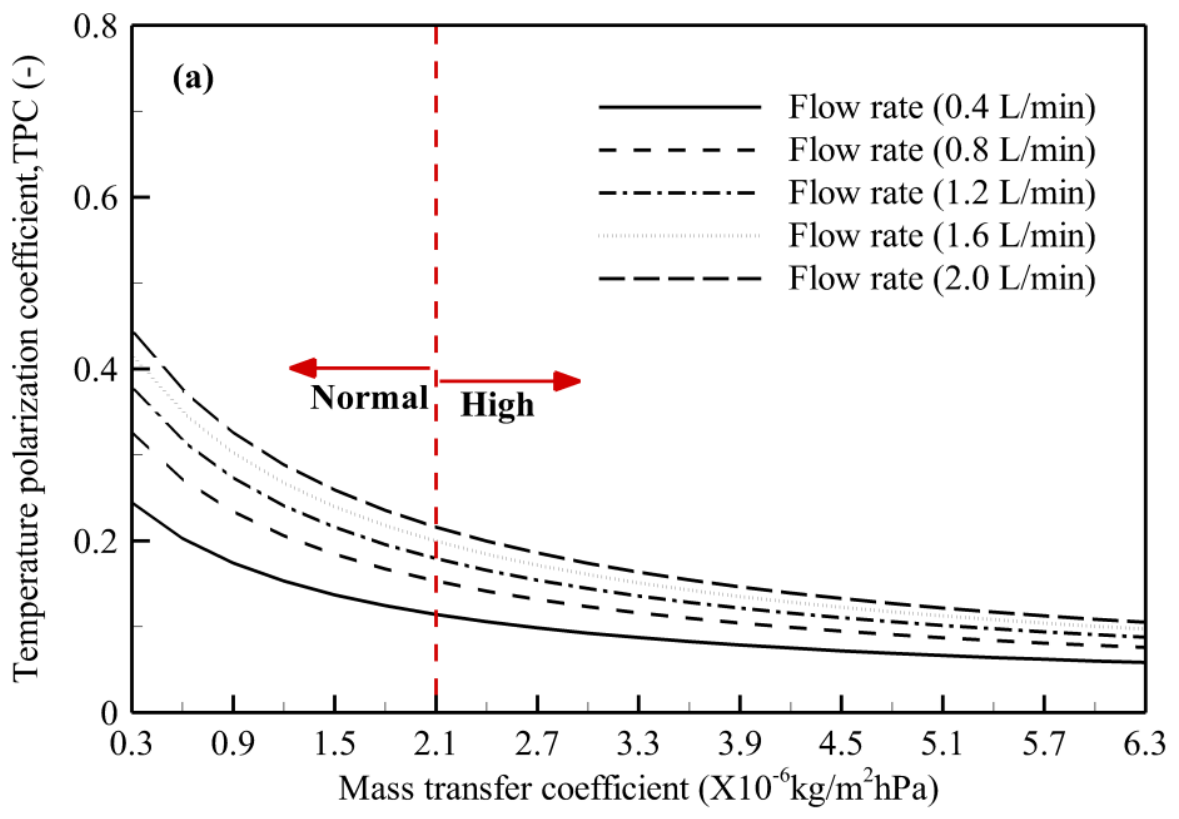



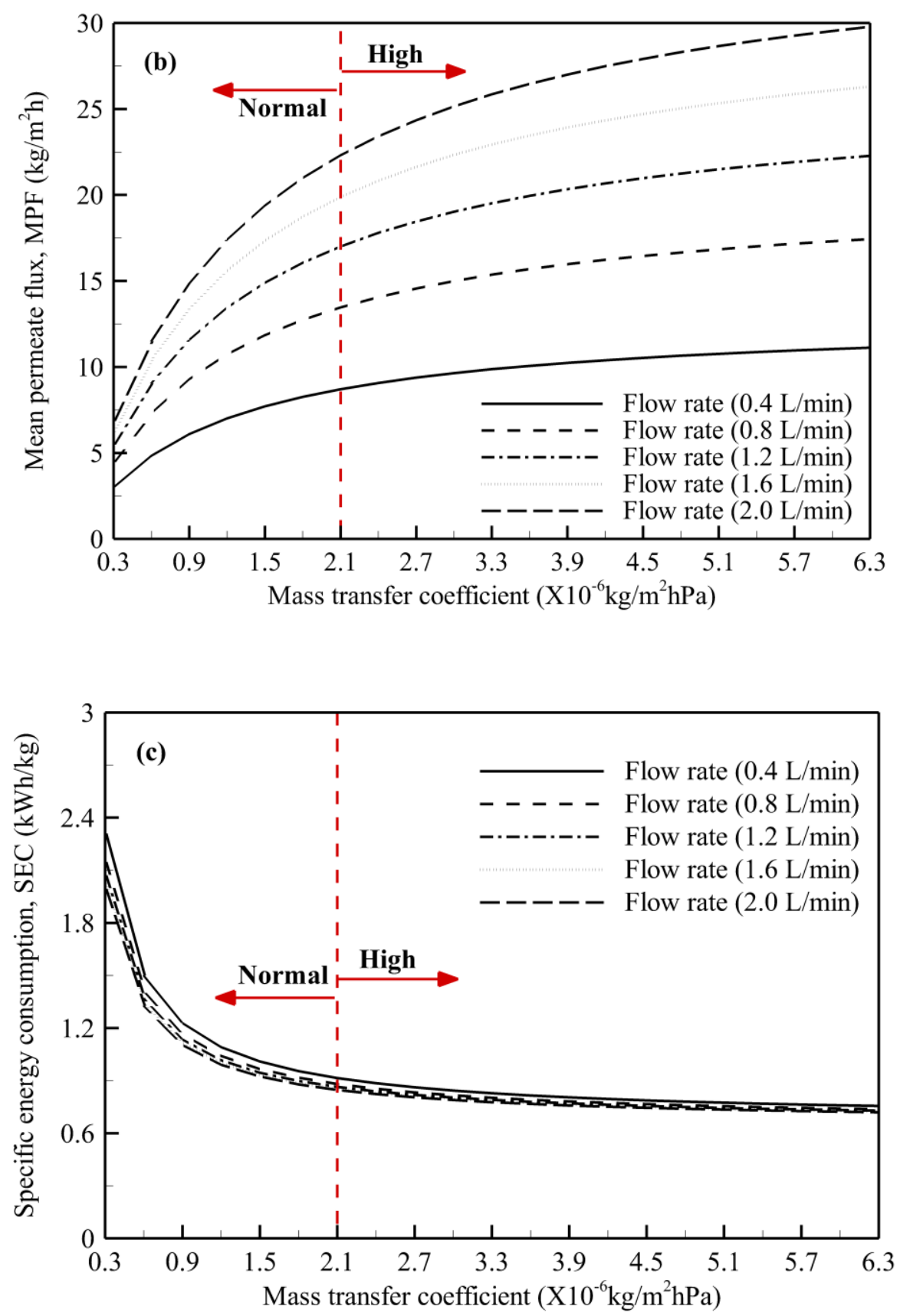

Figure 2. Effects of inlet feed and permeate flow rates and mass transfer coefficient on (a) TPC, (b) mean permeate flux, and (c) specific energy consumption at inlet feed temperature of $60{ }^{\circ} \mathrm{C}$, inlet permeate temperature of $30^{\circ} \mathrm{C}$, and inlet feed salinity of $40 \mathrm{~g} / \mathrm{L}$.

\subsection{How the MD performance could vary with an increased mass transfer coefficient}


As mentioned earlier, the model-based simulation study to assess the MD performance behavior (TPC, mean permeate flux, and specific energy consumption) was conducted at higher MTC values ranging from $2.1 \times 10^{-6}$ to $6.3 \times 10^{-6} \mathrm{~kg} / \mathrm{m}^{2} \mathrm{sPa}$, which is three times higher than the highest value reported in the literature, at various flow rates and the results are presented in Figures 2a-c (high zone). Figure 2a (high zone) shows the effect of the increased MTC on TPC at different inlet feed and permeate flow rates. With an increase of MTC from $2.1 \times 10^{-6}$ to $6.3 \times 10^{-6} \mathrm{~kg} / \mathrm{m}^{2} \mathrm{sPa}$, the TPC decreased from 0.11 to 0.06 at a flow rate of $0.4 \mathrm{~L} / \mathrm{min}$ and it decreased from 0.21 to 0.11 at $2.0 \mathrm{~L} / \mathrm{min}$. On the other hand, the mean permeate flux increased from 8.70 to $11.12 \mathrm{~kg} / \mathrm{m}^{2} \mathrm{~h}$ and from 22.31 to $29.78 \mathrm{~kg} / \mathrm{m}^{2} \mathrm{~h}$ at flow rates of $0.4 \mathrm{~L} / \mathrm{min}$ and $2.0 \mathrm{~L} / \mathrm{min}$, respectively, with the increase of MTC from 2.1 to $6.3 \times 10^{-6} \mathrm{~kg} / \mathrm{m}^{2} \mathrm{sPa}$ (Figure $2 \mathrm{~b}$ (high zone). With the same MTC and flow rate increase, mean permeate flux increased by $28 \%$ and $34 \%$, respectively, while their increases were higher $\left(157 \%\right.$ and $168 \%$ ) at $2.1 \times 10^{-6}$ and $6.3 \times 10^{-6} \mathrm{~kg} / \mathrm{m}^{2} \mathrm{sPa}$, respectively, implying that the convection heat transfer coefficient has strongly influenced the increase of mean permeate flux as water production. The reduction rate of specific energy consumption was significantly small with respect to the increase in the inlet feed and permeate flow rates, as shown in Figure 2c (high zone). Unlike the normal MTC ranges, the asymptotical increase in mean permeate flux was observed and the TPC and specific energy consumption also decreased asymptotically with an increase in MTC. In summary, MD performance at higher MTC is influenced more by the convection heat transfer coefficient (as flow rate) increase compared to MTC increase. Therefore, in the following section modified convection heat transfer coefficient (increased till 1.5 times as normal) was used in the simulation study. This study considered convection heat transfer coefficient by maximum 1.5 times, even though several studies have reported a higher value than 1.5 times [43]. The use of spacer can change the structure parameters of inner channel, thus the modified convection heat transfer equations (See. Eqs. (S7)-(S11)) and transportation equations (See. Eqs. (S13)-(S19)) are required. If spacer is not used, the $\varepsilon_{\mathrm{sp}}$ and $\mathrm{k}_{\mathrm{dc}}$ values are defined as 1 , and the $\mathrm{d}_{\mathrm{h}}$ value is also replaced by $\left(d_{h}=\frac{2 w_{c} h_{c}}{w_{c}+h_{c}}\right)$.

\subsection{Effect of enhanced convection heat transfer coefficient on membrane performance}

With high performance hydrophobic microporous membrane having high MTC, the convection heat transfer coefficient is more affecting the MD performance as described above. 
The modified (or enhanced) coefficient can be obtained with the use of spacers acting as a turbulent promoter or membrane support [26, 29-31, 42, 44] and the increase in the membrane surface roughness [34]. In the simulation study, convection heat transfer coefficient was varied from 1.0 (normal) to 1.5 times and employed in both feed and permeate channels. The modified coefficient $\left(h_{m, i}\right)$ was calculated using the following equation.

$h_{m, i}=k_{d c, i} h_{i}=C_{m} T_{m} h_{i} \quad(i=$ feed and peremate $)$

where $C H T_{m}$ is the modification constant, $h_{i}$ is the convection heat transfer coefficient, and $h_{m, i}$ is the modified convection heat transfer coefficient.

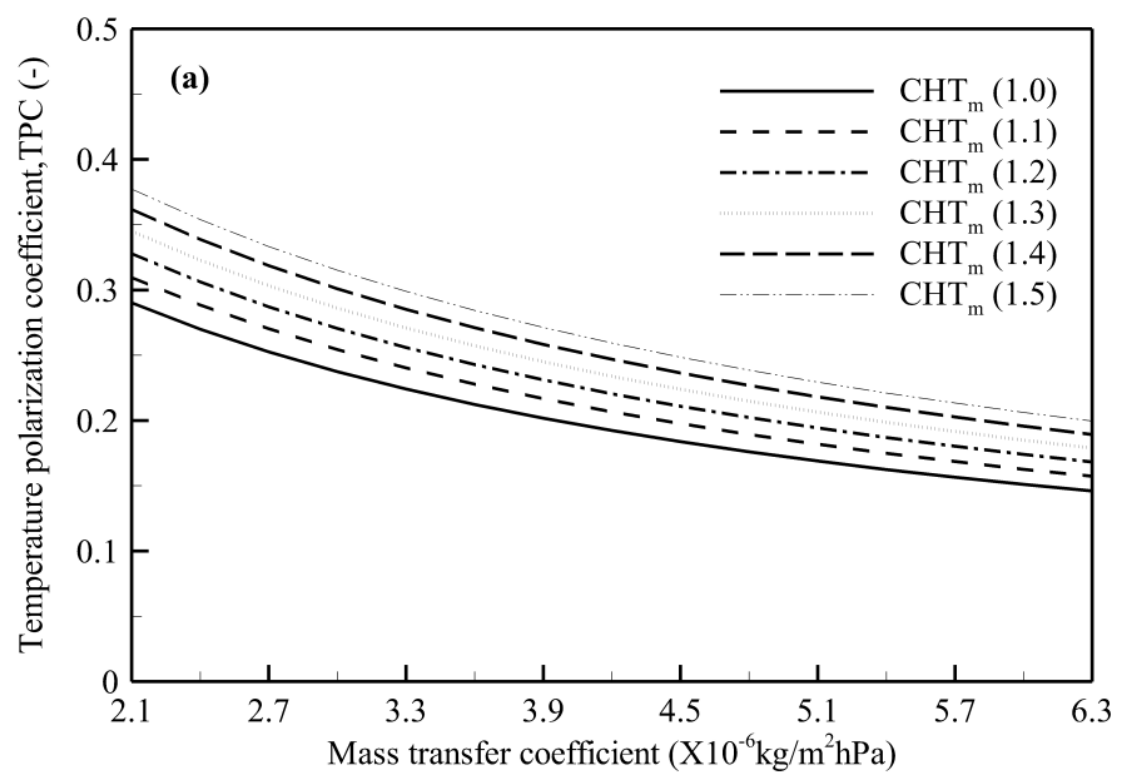



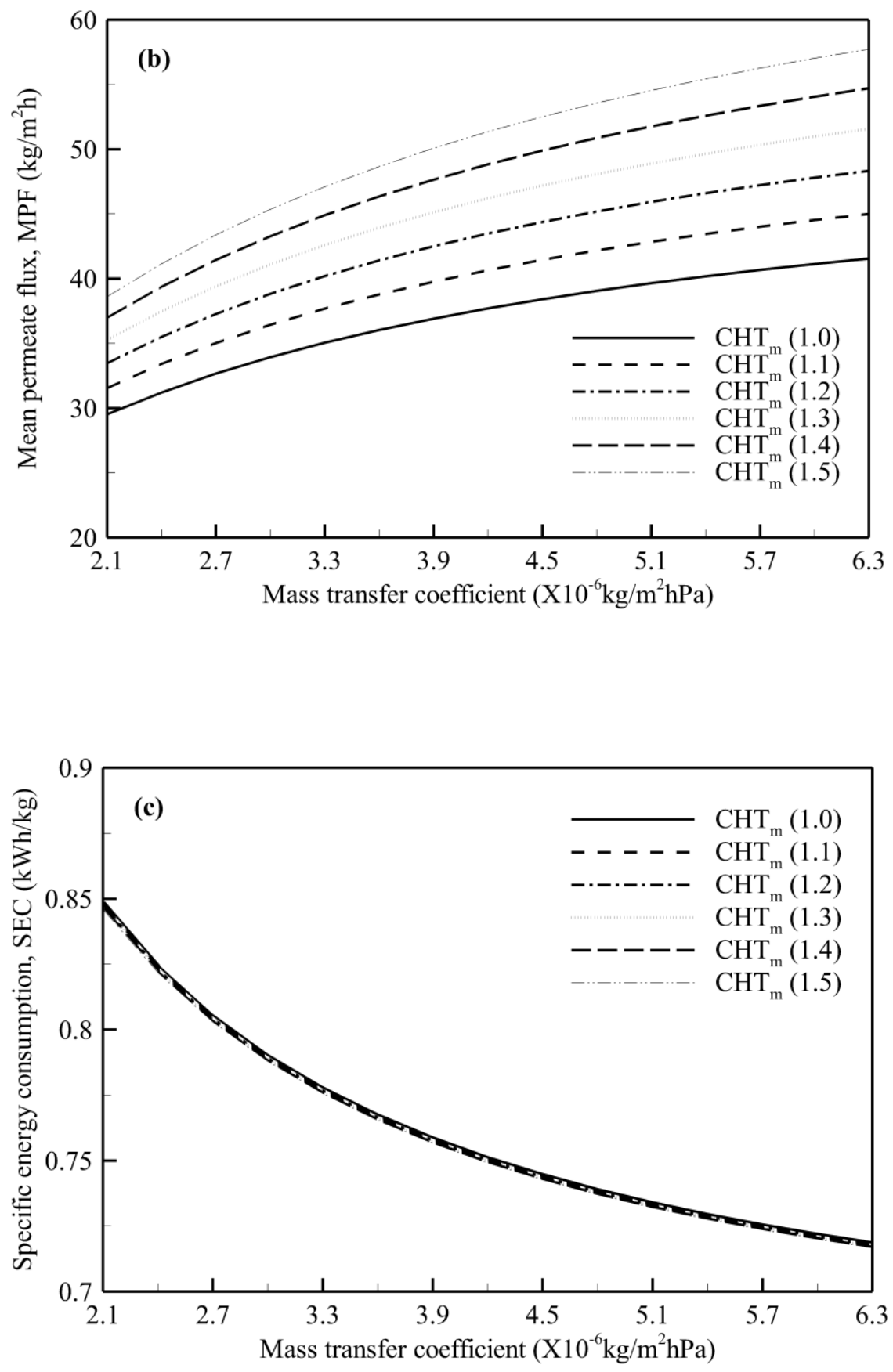

Figure 3. Effect of modified convection heat transfer coefficient ranging from 1 to 1.5 times and MTC on (a) TPC, (b) mean permeate flux, and (c) specific energy consumption at inlet feed and permeate temperatures of 60 and $30{ }^{\circ} \mathrm{C}$, respectively, inlet flow rates of $2.0 \mathrm{~L} / \mathrm{min}$, and inlet feed salinity of $40 \mathrm{~g} / \mathrm{L}$. 
The TPC increased from 0.29 to 0.38 with an increase in the convection heat transfer coefficient from 1.0 to 1.5 times at MTC of $2.1 \times 10^{-6} \mathrm{~kg} / \mathrm{m}^{2} \mathrm{sPa}$. At higher MTC $\left(6.3 \times 10^{-6}\right.$ $\mathrm{kg} / \mathrm{m}^{2} \mathrm{sPa}$ ), TPC increased from 0.15 to 0.20 (Figure $3 \mathrm{a}$ ). The increase of the MTC from $2.1 \times 10^{-6}$ to $6.3 \times 10^{-6} \mathrm{~kg} / \mathrm{m}^{2} \mathrm{sPa}$ led to a decrease of TPC by about $50 \%$ on average without the enhancement of the convection heat transfer coefficient $\left(\mathrm{CHT}_{\mathrm{m}}=1.0\right)$ while only a $50 \%$ of its increase resulted in $30 \%$ of TPC increase at MTC $=2.1 \times 10^{-6} \mathrm{~kg} / \mathrm{m}^{2} \mathrm{sPa}$. Figure $3 \mathrm{~b}$ shows that the mean permeate flux increased from 29.51 to $38.59 \mathrm{~kg} / \mathrm{m}^{2} \mathrm{~h}$ at $\mathrm{MTC}=2.1 \times 10^{-6} \mathrm{~kg} / \mathrm{m}^{2} \mathrm{sPa}$ and when this value reached $6.3 \times 10^{-6} \mathrm{~kg} / \mathrm{m}^{2} \mathrm{sPa}$, the flux is further increased from 41.55 to $57.73 \mathrm{~kg} / \mathrm{m}^{2} \mathrm{~h}$. Under this condition, the decrease of specific energy consumption was extremely marginal and was even constant at higher MTC ranges as the convection heat transfer coefficient increased, as shown in Figure 3c.

In fact, all the other parameters which were not considered in this study are also important. Parameters are associated with each other and affect the DCMD process performance, such as mean permeate flux, water production and specific energy consumption. However, in this study, we focused only on the effects of mass transfer and convection heat transfer on the DCMD performance as major factors.

\section{Discussions and remarks}

5.1 Effect of normal mass transfer coefficient $\left(<2.1 \times 10^{-6} \mathrm{~kg} / \mathrm{m}^{2} \mathrm{sPa}\right)$ on TPC, mean permeate flux, and specific energy consumption 

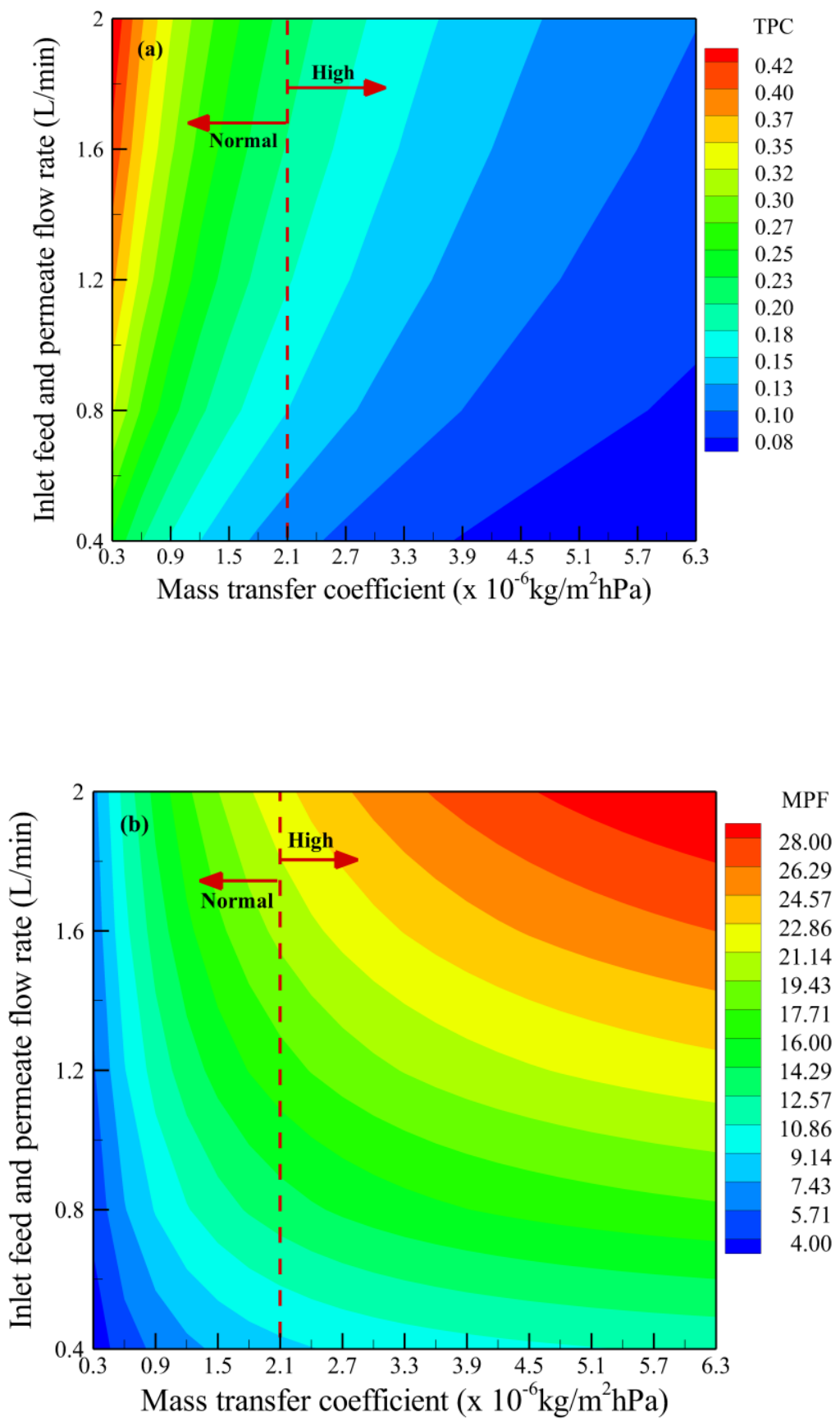


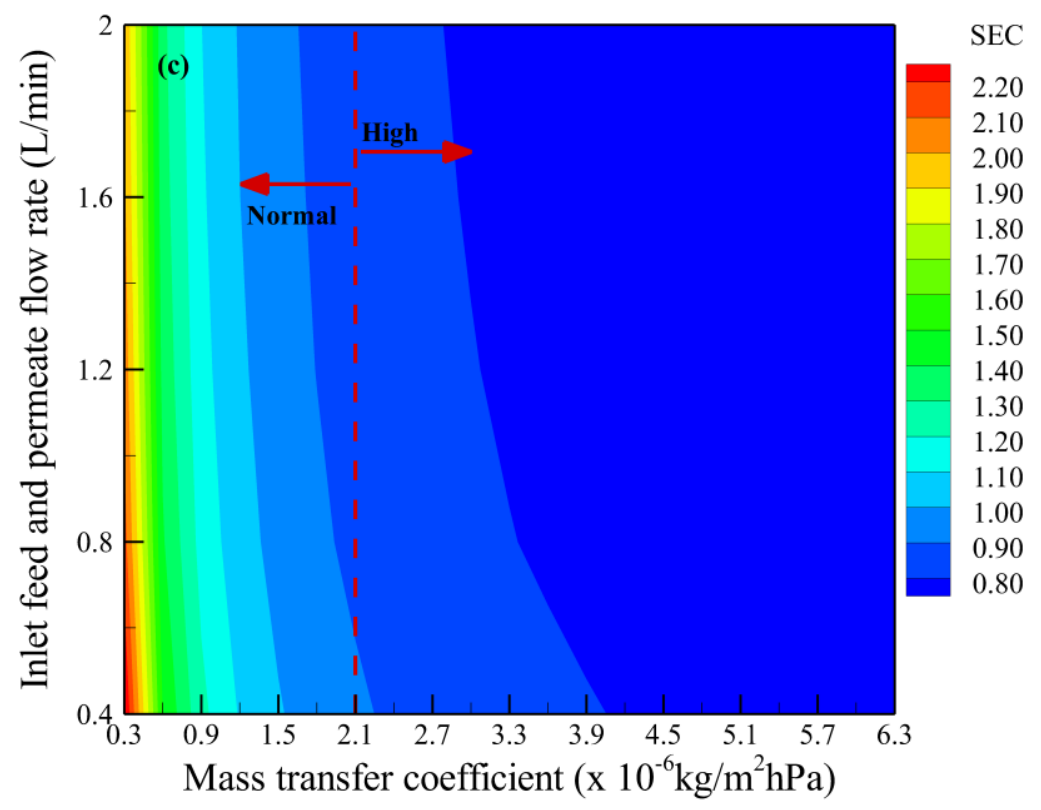

Figure 4. Effect of mass transfer coefficient and inlet feed and permeate flow rates on (a) TPC, (b) mean permeate flux, and (c) specific energy consumption.

In order to better understand this investigation showing the contour graph of the effect of MTC and inlet feed and permeate flow rates on (a) TPC, (b) mean permeate flux, and (c) specific energy consumption simulation results are presented in Figures 4a-c. As shown in Figure 4a (normal zone), the TPC decreased with an increase in MTC. This is because the transmembrane temperature difference across the membrane must be balanced (in terms of heat and mass transfer) between the convection heat transfer coefficient from the bulk to liquid/vapor interface in the feed and permeate sides, and the latent heat and conduction heat loss across the membrane, as shown in Eqs. (S5) (S12) according to the first law of thermodynamics. Hence, the decrease in the TPC was caused by an increase in MTC under constant thermal conductivity. In other words, if the MTC is sufficiently high, the transmembrane temperature difference will be significantly low. Furthermore, the higher inlet flow rates (at high Reynolds number) lead to an increase of the convection heat transfer coefficient, which transfers the heat from bulk to the liquid/vapor interface in the feed and permeate sides, consequently the transmembrane temperature difference increases. Therefore, this increase led to higher driving force conjugated by enhanced TPC. Figure 4b (normal zone) shows 
that the effect of flow rates on the mean permeate flux at the low ranges of MTC was smaller than that at the high ranges. The low MTC indicated that water vapor could transfer a low amount of latent heat across the membrane, thus at lower MTC, the transmembrane temperature difference and driving force were maintained compared to that at higher MTC. On the other hand, the lowered transmembrane temperature difference caused by the increased MTC can be increased again by an increase of the convection heat transfer coefficient and subsequently led to a mean permeate flux increase. More specifically, the mean permeate flux increased by about $35 \%$ and $63 \%$ with five times increase in flow rates (from 0.4 to $2.0 \mathrm{~L} / \mathrm{min}$ ) at MTC $=0.3 \times 10^{-6}$ and $2.1 \times 10^{-6} \mathrm{~kg} / \mathrm{m}^{2} \mathrm{sPa}$, respectively, while it increased up to $123 \%$ and $169 \%$ with an increase in MTC of about three times at two different flow rates of 0.4 and $2.0 \mathrm{~L} / \mathrm{min}$, respectively. This clearly showed that the effect of MTC on the mean permeate flux is more significant than flow rates, particularly at low ranges, since the TPC reduction rate was not high considering the MTC increment rate, as observed in Figure 4a (normal zone). Higher MTC led to a low conduction heat loss due to the small transmembrane temperature difference, thus the specific energy consumption decreased with an increase in MTC but the reduction was not significant, as can be seen from the simulation results presented in Figure 4c (normal zone). However, the effect of flow rate on specific energy consumption was marginally low $(<1 \%)$ because the thermal energy in the bulk was only consumed for water evaporation at the liquid/vapor interface of the membrane.

5.2 Effect of high mass transfer coefficient $\left(>2.1 \times 10^{-6} \mathrm{~kg} / \mathrm{m}^{2} \mathrm{sPa}\right)$ on TPC, mean permeate flux, and specific energy consumption

In the high ranges of MTC (from 2.1 to $4.2 \times 10^{-6} \mathrm{~kg} / \mathrm{m}^{2} \mathrm{sPa}$ ), the decreasing rate of TPC to MTC was high as can be seen from Figure $4 \mathrm{a}$ (high), while the TPC decreased asymptotically with respect to MTC values ranging from 4.2 to $6.3 \times 10^{-6} \mathrm{~kg} / \mathrm{m}^{2} \mathrm{sPa}$ indicating that when the latter is sufficiently high (in this case, by $4.2 \times 10^{-6} \mathrm{~kg} / \mathrm{m}^{2} \mathrm{sPa}$ ), the effect of inlet flow rates on TPC was relatively significant compared to the higher ranges of MTC. In other words, the effect of the convection heat transfer coefficient on TPC became marginal beyond a certain MTC value and this indicated that the increase with MTC was very small even though when the convection heat transfer coefficient increased. Simulation results presented in Figure 4b (high zone) clearly indicate that with an increase of flow rate the mean permeate flux increased significantly. It is also found that the flow rates had less effect on mean permeate flux at lower MTC values $\left(<4.2 \times 10^{-6}\right.$ 
$\mathrm{kg} / \mathrm{m}^{2} \mathrm{sPa}$ ), while the convection heat transfer coefficient considerably affected the mean permeate flux at higher MTC values implying that mean permeate flux is influenced by the flow rates as MTC increased. The effect of the inlet flow rate on specific energy consumption was marginally low (Figure 4c (high zone)) indicating that although the higher convection heat transfer coefficient can increase the water production and transmembrane temperature difference as driving force, it causes a higher conduction heat loss. In summary, the higher convection heat transfer coefficient can increase the driving force, however it can also increase the conduction heat loss, simultaneously. In the MD process, the specific energy consumption is in a tradeoff between the driving force and conduction heat loss. Interestingly, the TPC and specific energy consumption had a similar tendency with respect to the MTC and flow rates, but the TPC was slightly more influenced by the convection heat transfer coefficient whereas MTC affected the specific energy consumption. However, the trends of the mean permeate flux was dominantly affected by MTC at lower values, compared to flow rates, which is the opposite when higher MTC is employed probably due to the low TPC under this condition. In summary, MD performance at increased MTC was more influenced by the convection heat transfer coefficient increase compared to the increase of the MTC itself.

\subsection{Effect of modified convection heat transfer coefficient with an increased mass transfer} coefficient on TPC, mean permeate flux, and specific energy consumption

Figure 5a shows that even though the convection heat transfer coefficient is increased, TPC in the flow channel was not significantly increased due to the high latent heat transferred across the membrane that makes the increase of TPC difficult. As can be seen from Figure 5b, the increase of mean permeate flux was significant as the convection heat transfer coefficient increased and its growth pattern was relatively linear indicating that it was affected by MTC constantly. This is also because its increase led to a reduction of thermal energy transportation limitation within the boundary layer and across the membrane. Figure 5c indicates that the conduction heat loss removed mostly by the increased MTC had a positive effect on mean permeate flux. 

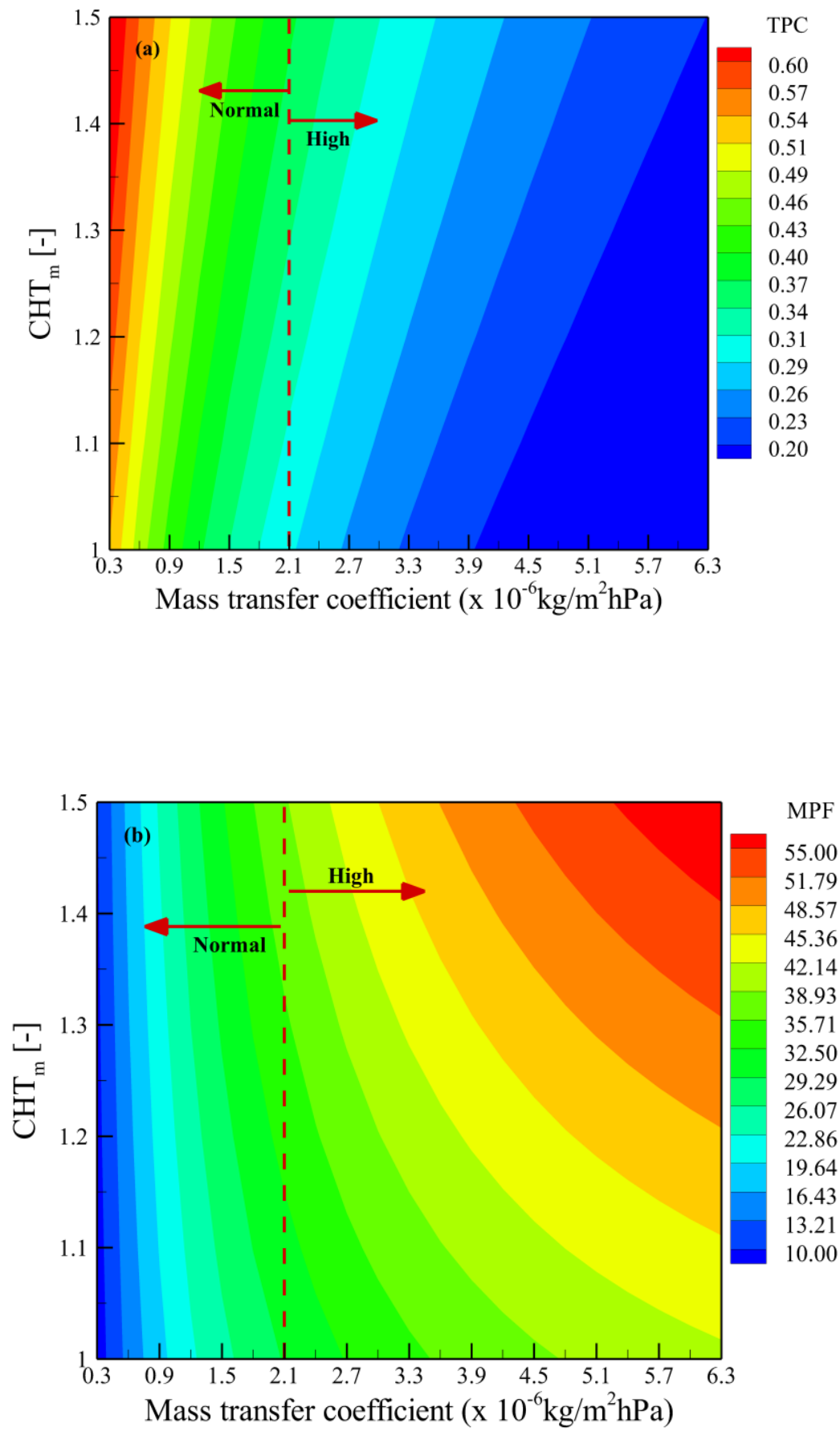


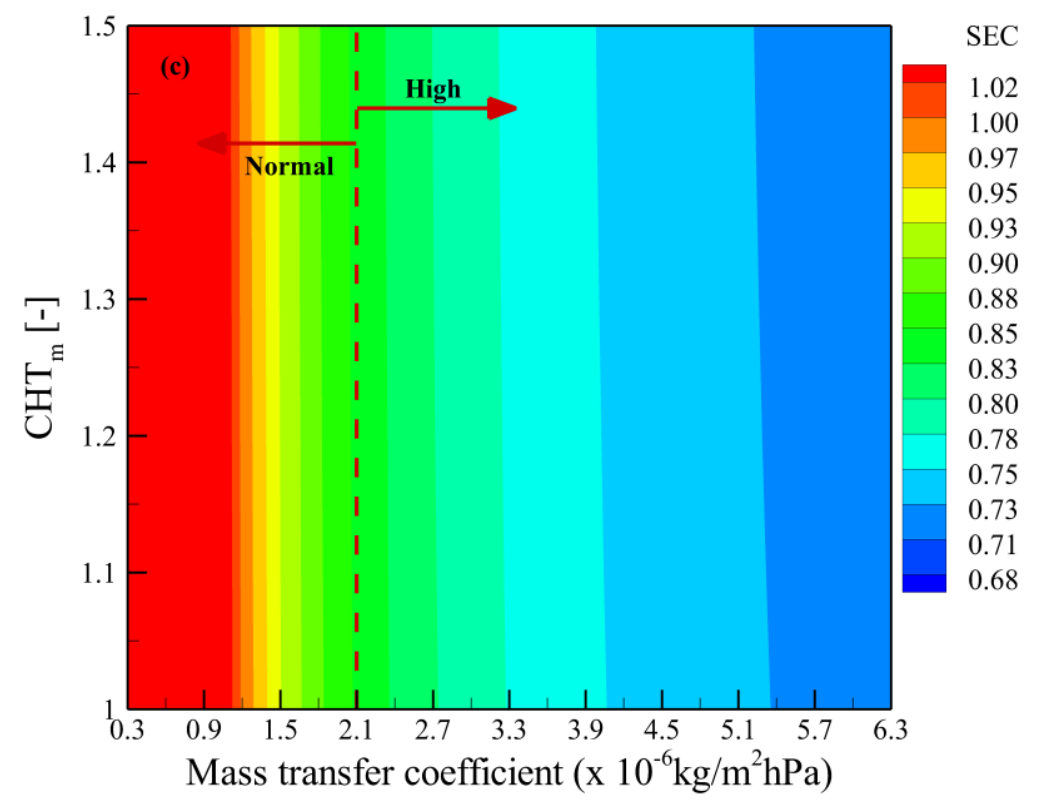

Figure 5. Effect of modified convection heat transfer coefficient $\left(\mathrm{CHT}_{\mathrm{m}}\right)$ and high MTC on (a) TPC, (b) mean permeate flux, and (c) specific energy consumption.

From this simulation study, it is clearly shown that the mean permeate flux has significantly increased with an increase of the modified convection heat transfer coefficient, however the increase of TPC and the decrease of specific energy consumption were still insignificant. It means that the mean permeate flux could be enhanced with the modification of convection heat transfer coefficient at higher MTC ranges $\left(>2.1 \times 10^{-6} \mathrm{~kg} / \mathrm{m}^{2} \mathrm{sPa}\right)$ with a marginal increase of TPC and decrease of specific energy consumption.

\section{Conclusions}

This study is the first theoretical simulation investigation helping to further understand the MD performance behavior (TPC, mean permeate flux and specific energy consumption) at various MTC values and flow rates (as convection heat transfer coefficient). The key results obtained from this study are summarized as follows:

- At low ranges of MTC $\left(<2.1 \times 10^{-6} \mathrm{~kg} / \mathrm{m}^{2} \mathrm{sPa}\right)$, MD had higher TPC indicating that a low amount of thermal energy could be transferred across the membrane and subsequently led 
to an increase of TPC. As the latter is sufficiently high at this range, the effect of the convection heat transfer coefficient on the MD performance was not significant. In addition, an increase in mean permeate flux was higher with an increase of MTC than that of the convection heat transfer coefficient.

- However, when the MTC is increased $\left(>2.1 \times 10^{-6} \mathrm{~kg} / \mathrm{m}^{2} \mathrm{sPa}\right)$, the effect of the convection heat transfer coefficient on mean permeate flux increased. In other words, only a slight increase of TPC could enhance the mean permeate flux at high ranges of MTC.

- Moreover, it was not suitable to increase the convection heat transfer coefficient for enhancing mean permeate flux at low MTC ranges where TPC is high.

- Improving MTC at low ranges is more important than that at high ranges because the heat transfer resistance becomes dominant and hence the convection heat transfer coefficient must be increased for MD performance improvement.

- The presented values of TPC, mean permeate flux, and specific energy consumption could be varied with modifying the channel structures such as channel width, length and depth, and the operating conditions such as inlet pressure, velocity and temperature.

- As shown by the simulation results, the currently reported MTC $\left(<2.1 \times 10^{-6} \mathrm{~kg} / \mathrm{m}^{2} \mathrm{sPa}\right)$ is sufficiently high; but an appropriate MD module designed by using a spacer, controlling the membrane surface roughness and reducing the channel thickness is desired to increase the convection heat transfer coefficient and TPC in the channel to obtain higher flux.

\section{Acknowledgement}

The research reported in this paper was supported by funding from King Abdullah University of Science and Technology (KAUST), Saudi Arabia.

\section{References}

[1] J.-G. Lee, Y.-D. Kim, W.-S. Kim, L. Francis, G. Amy, N. Ghaffour, Performance modeling of direct contact membrane distillation (DCMD) seawater desalination process using a commercial composite membrane, J. Membr. Sci. 478 (2015) 85-95.

[2] S. Al-Obaidani, E. Curcio, F. Macedonio, G. Di Profio, H. Al-Hinai, E. Drioli, Potential of membrane distillation in seawater desalination: thermal efficiency, sensitivity study and cost estimation, J. Membr. Sci. 323 (2008) 85-98. 
[3] M. Khayet, T. Matsuura, Membrane distillation: principles and applications, Elsevier, 2011.

[4] Y.-D. Kim, K. Thu, N. Ghaffour, K.C. Ng, Performance investigation of a solar-assisted direct contact membrane distillation system, J. Membr. Sci. 427 (2013) 345-364.

[5] L. Eykens, K. De Sitter, C. Dotremont, L. Pinoy, B. Van der Bruggen, How To Optimize the Membrane Properties for Membrane Distillation: A Review, Ind. Eng. Chem. Res. 55 (2016) 9333-9343.

[6] N. Ghaffour, J. Bundschuh, H. Mahmoudi, M.F. Goosen, Renewable energy-driven desalination technologies: A comprehensive review on challenges and potential applications of integrated systems, Desalination 356 (2015) 94-114.

[7] P.A. Hogan, Sudjito, A.G. Fane, G.L. Morrison, Proceedings of the Twelfth International Symposium on Desalination and Water Re-useDesalination by solar heated membrane distillation, Desalination 81 (1991) 81-90.

[8] J. Xu, Y.B. Singh, G.L. Amy, N. Ghaffour, Effect of operating parameters and membrane characteristics on air gap membrane distillation performance for the treatment of highly saline water, J. Membr. Sci. 512 (2016) 73-82.

[9] A.S. Alsaadi, L. Francis, H. Maab, G.L. Amy, N. Ghaffour, Evaluation of air gap membrane distillation process running under sub-atmospheric conditions: Experimental and simulation studies, J. Membr. Sci. 489 (2015) 73-80.

[10] G. Naidu, S. Jeong, S. Vigneswaran, T.-M. Hwang, Y.-J. Choi, S.-H. Kim, A review on fouling of membrane distillation, Desalination Water Treat. 57 (2016) 10052-10076.

[11] A. Alkhudhiri, N. Darwish, N. Hilal, Membrane distillation: A comprehensive review, Desalination 287 (2012) 2-18.

[12] M.S. El-Bourawi, Z. Ding, R. Ma, M. Khayet, A framework for better understanding membrane distillation separation process, J. Membr. Sci. 285 (2006) 4-29.

[13] L. Francis, N. Ghaffour, A. Alsaadi, S. Nunes, G. Amy, Performance evaluation of the DCMD desalination process under bench scale and large scale module operating conditions, J. Membr. Sci. 455 (2014) 103-112.

[14] M. Khayet, J. Mengual, T. Matsuura, Porous hydrophobic/hydrophilic composite membranes: application in desalination using direct contact membrane distillation, J. Membr. Sci. 252 (2005) 101-113. [15] J. Lee, S. Jeong, Z. Liu, Progress and challenges of carbon nanotube membrane in water treatment, Crit Rev Env Sci Tec. 46 (2016) 11-12.

[16] S. Roy, M. Bhadra, S. Mitra, Enhanced desalination via functionalized carbon nanotube immobilized membrane in direct contact membrane distillation, Sep. Purif. Technol. 136 (2014) 58-65.

[17] R. Huo, Z. Gu, K. Zuo, G. Zhao, Preparation and properties of PVDF-fabric composite membrane for membrane distillation, Desalination, 249 (2009) 910-913. 
[18] J. Prince, V. Anbharasi, T. Shanmugasundaram, G. Singh, Preparation and characterization of novel triple layer hydrophilic-hydrophobic composite membrane for desalination using air gap membrane distillation, Sep. Purif. Technol. 118 (2013) 598-603.

[19] M. Qtaishat, M. Khayet, T. Matsuura, Guidelines for preparation of higher flux hydrophobic/hydrophilic composite membranes for membrane distillation, J. Membr. Sci. 329 (2009) 193-200.

[20] M. Qtaishat, D. Rana, M. Khayet, T. Matsuura, Preparation and characterization of novel hydrophobic/hydrophilic polyetherimide composite membranes for desalination by direct contact membrane distillation, J. Membr. Sci. 327 (2009) 264-273.

[21] A. Kyoungjin An, E.-J. Lee, J. Guo, S. Jeong, J.-G. Lee, N. Ghaffour, Enhanced vapor transport in membrane distillation via functionalized carbon nanotubes anchored into electrospun nanofibres, Sci. Rep. 7 (2017) 41562.

[22] C. Yang, X.-M. Li, J. Gilron, D.-f. Kong, Y. Yin, Y. Oren, C. Linder, T. He, CF 4 plasma-modified superhydrophobic PVDF membranes for direct contact membrane distillation, J. Membr. Sci. 456 (2014) 155-161.

[23] L. Martínez-Díez, M.I. Vazquez-Gonzalez, Temperature and concentration polarization in membrane distillation of aqueous salt solutions, J. Membr. Sci. 156 (1999) 265-273.

[24] A.S. Alsaadi, L. Francis, G.L. Amy, N. Ghaffour, Experimental and theoretical analyses of temperature polarization effect in vacuum membrane distillation, J. Membr. Sci. 471 (2014) 138-148. [25] S. Al-Sharif, M. Albeirutty, A. Cipollina, G. Micale, Modelling flow and heat transfer in spacerfilled membrane distillation channels using open source CFD code, Desalination, 311 (2013) 103-112. [26] M.N. Chernyshov, G.W. Meindersma, A.B. de Haan, Comparison of spacers for temperature polarization reduction in air gap membrane distillation, Desalination, 183 (2005) 363-374.

[27] A. Da Costa, A. Fane, D. Wiley, Spacer characterization and pressure drop modelling in spacer-filled channels for ultrafiltration, J. Membr. Sci. 87 (1994) 79-98.

[28] S. Lin, N.Y. Yip, M. Elimelech, Direct contact membrane distillation with heat recovery:

Thermodynamic insights from module scale modeling, J. Membr. Sci. 453 (2014) 498-515.

[29] L. Martínez-Díez, M.I. Vázquez-González, F.J. Florido-Díaz, Study of membrane distillation using channel spacers, J. Membr. Sci. 144 (1998) 45-56.

[30] J. Phattaranawik, R. Jiraratananon, A. Fane, Effects of net-type spacers on heat and mass transfer in direct contact membrane distillation and comparison with ultrafiltration studies, J. Membr. Sci. 217 (2003) 193-206.

[31] J. Phattaranawik, R. Jiraratananon, A. Fane, C. Halim, Mass flux enhancement using spacer filled channels in direct contact membrane distillation, J. Membr. Sci. 187 (2001) 193-201. 
[32] E. Achenbach, The effect of surface roughness on the heat transfer from a circular cylinder to the cross flow of air, Int. J. Heat Mass Transfer, 20 (1977) 359-369.

[33] N. Abuaf, R. Bunker, C. Lee, Effects of surface roughness on heat transfer and aerodynamic performance of turbine airfoils, in: ASME 1997 International Gas Turbine and Aeroengine Congress and Exhibition, ASME, 1997, V003T009A001.

[34] S.G. Kandlikar, S. Joshi, S. Tian, Effect of Surface Roughness on Heat Transfer and Fluid Flow Characteristics at Low Reynolds Numbers in Small Diameter Tubes, Heat Transfer Eng. 24 (2003) 4-16.

[35] S. Shim, J. Lee, W. Kim, Performance simulation of a multi-VMD desalination process including the recycle flow, Desalination, 338 (2014) 39-48.

[36] J. Phattaranawik, R. Jiraratananon, A.G. Fane, C. Halim, Mass flux enhancement using spacer filled channels in direct contact membrane distillation, J. Membr. Sci. 187 (2001) 193-201.

[37] J.-G. Lee, W.-S. Kim, Numerical modeling of the vacuum membrane distillation process, Desalination, 331 (2013) 46-55.

[38] J.-G. Lee, W.-S. Kim, Numerical study on multi-stage vacuum membrane distillation with economic evaluation, Desalination, 339 (2014) 54-67.

[39] J.-G. Lee, Y.-D. Kim, S.-M. Shim, B.-G. Im, W.-S. Kim, Numerical study of a hybrid multi-stage vacuum membrane distillation and pressure-retarded osmosis system, Desalination, 363 (2015) 82-91. [40] J.-G. Lee, E.-J. Lee, S. Jeong, J. Guo, A.K. An, H. Guo, J. Kim, T. Leiknes, N. Ghaffour, Theoretical modeling and experimental validation of transport and separation properties of carbon nanotube electrospun membrane distillation, J. Membr. Sci. 526 (2017) 395-408.

[41] J.-G. Lee, W.-S. Kim, J.-S. Choi, N. Ghaffour, Y.-D. Kim, A novel multi-stage direct contact membrane distillation module: Design, experimental and theoretical approaches, Water Res. 107 (2016) 47-56.

[42] J. Phattaranawik, R. Jiraratananon, A. Fane, Heat transport and membrane distillation coefficients in direct contact membrane distillation, J. Membr. Sci. 212 (2003) 177-193.

[43] A. Tamburini, M. Renda, A. Cipollina, G. Micale, M. Ciofalo, Investigation of heat transfer in spacer-filled channels by experiments and direct numerical simulations, Int. J. Heat Mass Transf. 93 (2016) 1190-1205.

[44] N. Ghaffour, R. Jassim, T. Khir, Flux enhancement by using helical baffles in ultrafiltration of suspended solids, Desalination 167 (2004) 201-207. 